\title{
Álvaro Molina (ed.), La Historia del Arte en España: devenir, discursos y propuestas. Madrid: Ediciones Polifemo, 2016, 557 págs.
}

La adaptación de los estudios universitarios españoles al Espacio Europeo de Educación Superior condujo a proponer la eliminación de la licenciatura o futuro grado en Historia del Arte. Este planteamiento tuvo lugar durante el curso 2004-2005 y provocó la movilización de la mayor parte del mundo académico. Afortunadamente se logró frenar esta pretensión auspiciada desde el ámbito ministerial, pero la amenaza ya se comenzó a cernir entonces sobre los estudios universitarios de Historia del Arte. Un grupo de docentes e investigadores, preocupados por el devenir de esta disciplina en España, comenzó a tomar conciencia de su precariedad académica, entre ellos la profesora Jesusa Vega, quien lideró un proyecto I+D+i de la convocatoria del año 2012 que llevaba por título La Historia del Arte en España: devenir, discursos y propuestas; el resultado final del trabajo desarrollado por sus integrantes es el libro homónimo que se trata en esta reseña.

El hilo conductor que va guiando los distintos capítulos que conforman el libro es la reflexión crítica sobre el devenir de la disciplina y sus propuestas de futuro. No se trata por tanto de una obra centrada sólo en exponer la historia de la Historia del Arte en España desde su institucionalización en 1904 hasta la actualidad, sino que trasciende hacia la reflexión epistemológica proponiendo al lector nuevas perspectivas de estudio con los que se han obtenido resultados satisfactorios. De modo que el desarrollo histórico de la disciplina con el que comienza la obra ayuda a comprender las causas de su cuestionamiento a comienzos del presente siglo, mientras que la presentación de otras maneras de estudiar el fenómeno artístico procura su proyección hacia el futuro.

Como explica el editor de la obra en su introducción, el libro está organizado en tres epígrafes que recogen y organizan el contenido temático de los distintos ensayos. En el primero, que lleva por título "Fundamentos", destaca la aportación de Jesusa Vega. Creo que el ensayo de Vega es el alma del libro, pues en sus cuantiosas páginas encontramos reflejados los objetivos que guiaron el citado proyecto $\mathrm{I}+\mathrm{D}+\mathrm{i}$ de la que fue directora. Además de encuadrar y contextualizar los contenidos del resto del volumen, la autora hace propuestas de gran calado que invitan desde sus primeros párrafos a la reflexión, especialmente acerca de la dificultad que tenemos algunos historiadores del arte para explicar el alcance de nuestro objeto de estudio; este gesto, como la profesora Vega señala, es indicativo de la falta de reflexión disciplinar.

Siguiendo su propuesta, sería deseable que se abordara el estudio de la historia de la disciplina desde distintos puntos de vista: analizando los escritos de los autores, la evolución de su pensamiento, las circunstancias en las que desarrollaron su trabajo, el contexto intelectual y político en el que publicaron y ejercieron y el medio en el que se dieron a conocer. Solo conociendo el proceso de desarrollo, institucionalización y consolidación de los estudios histórico-artísticos en España podemos analizar el origen de nuestra ciencia, y por tanto valorarla y proyectarla hacia el futuro, defendiendo así su continuidad.

A la aportación de la profesora Vega sigue la de Javier Portús, buen conocedor de la historiografía de la pintura en España, quien se ha ocupado de recordar cómo debe ampliarse la perspectiva desde la cual se estudia actualmente el arte español; sugiere la 
atención y cuidado de los contactos internacionales y la necesidad de superar la tendencia casticista de anteriores estudios. Juan Carlos Ruiz Souza dedica su colaboración a trazar un estado de la cuestión historiográfica en torno al concepto de arte mudéjar, especialmente sugestivo por sus connotaciones culturales, políticas e ideológicas, y lanza además algunas propuestas de futuro.

Una segunda sección del libro está destinada a derribar las barreras establecidas desde época decimonónica acerca del objeto de estudio de la Historia del Arte y su ámbito territorial: "Más allá de las Bellas Artes y de Occidente". Carmen Bernárdez aborda el problema de la materialidad del objeto artístico, cuestión que propone repensar, sugerencia que justifica por la desatención que ha habido en la Historia del Arte hacia ese concepto y sobre todo porque la materialidad interesa a muchas áreas de conocimiento. Isabel Cervera dedica su escrito a revisar la fortuna historiográfica de los estudios sobre el arte de Asia Oriental en España, así como de sus líneas de trabajo e investigación. María Rosón ofrece una exposición acerca de tendencias en la investigación de la historia de la fotografía en España y con qué problemas puede encontrarse el investigador; finaliza su ensayo con un estudio acerca del patrimonio fotográfico.

La tercera y última parte del libro lleva por título "Discursos, contextos, escenarios" y el encargado de abrirla es el editor del libro, Álvaro Molina, quien pone de manifiesto la desatención y maltrato que ha habido hacia el siglo XVIII en la historiografía española; como el autor indica, este ha sido etiquetado como un siglo oscuro y tradicionalmente carente de raíces nacionales. Molina propone la incorporación del concepto de visualidad al discurso dieciochesco y el estudio del arte español de dicha centuria a través de nuevos métodos caracterizados por su interdisciplinariedad.

Noemí de Haro traza un ameno recorrido por la trayectoria laboral, intelectual y política de los críticos, teóricos e historiadores del arte José María Moreno Galván y Valeriano Bozal, ejemplos de disidencia de la narración de la Historia el Arte oficial en España. La autora atiende fundamentalmente al enfoque metodológico del trabajo de dichos personajes, los objetos de estudio de los que se han ocupado y cómo estos afectan a la memoria del pasado y al presente. Isabel Tejeda se ocupa de abordar una de las más debatidas cuestiones sobre museografía española: la dificultad existente para imbricar en el relato de la historia de la pintura española el escalón existente entre Goya y Picasso. Para exponer esta problemática, recurre al examen de la reciente revitalización en el Museo del Prado de los fondos de pintura española del siglo XIX. Por último, Iñaki Estella reconoce a través de su aportación la importancia historiográfica del proyecto de investigación Desacuerdos: sobre arte, políticas y esfera pública en el Estado español y cómo este ha servido para comprender la historia del arte en nuestro país desde finales del franquismo gracias a la aportación de nuevos temas, perspectivas y metodologías de trabajo al margen de la Universidad.

Finalmente el libro se complementa con una cuidada selección de lecturas incluidas en un disco compacto anexo que ayudan a comprender el desarrollo de la disciplina. Es a través de los textos producidos por la historiografía artística como podemos conocer los métodos de trabajos empleados por la Historia del Arte en España y su epistemología. Considero necesario destacar entre todos ellos el discurso de ingreso a la Academia de San Fernando de Enrique Lafuente Ferrari el 15 de enero de 1951, titulado "La fundamentación y los problemas de la Historia del Arte", donde su objetivo es rebatir la teoría de los estilos y los planteamientos de Wölfflin, tan en boga aún hoy en día. Otro 
texto muy señalado es "Las Bellas Artes, nueva entre las disciplinas universitarias", discurso de Elías Tormo leído con motivo de la inauguración del curso académico 19091910 que como bien ha señalado Vega, sirvió para justificar ante la Academia la necesidad de la Historia del Arte.

Podemos valernos de la inspiración que ofrecen textos como el de Tormo para tomar conciencia acerca de la necesidad de repensar nuestra disciplina y así reflexionar acerca de para qué sirve la Historia del Arte, una disciplina cuya autonomía ha sido recientemente cuestionada, y en su caso, legitimar su continuidad. Como ya ha advertido Jesusa Vega, si la Historia del Arte quiere tener futuro debe servir para algo, y para ponderar la utilidad de la disciplina, debe comenzarse por pensar y repensar su desarrollo histórico.

Carmen de Tena Ramírez

Departamento de Historia del Arte. Universidad de Sevilla.

carmendetenaramirez@gmail.com

Fecha de recepción: 5 de mayo de 2018.

Fecha de aceptación: 15 de abril de 2018.

Publicación: 30 de junio de 2018.

Para citar este artículo: Carmen de Tena Ramírez, “Álvaro Molina (ed.), La Historia del Arte en España: devenir, discursos y propuestas. Madrid: Ediciones Polifemo, 2016, 557 págs.", Historiografías, 15 (enero-junio, 2018): 127-129. 